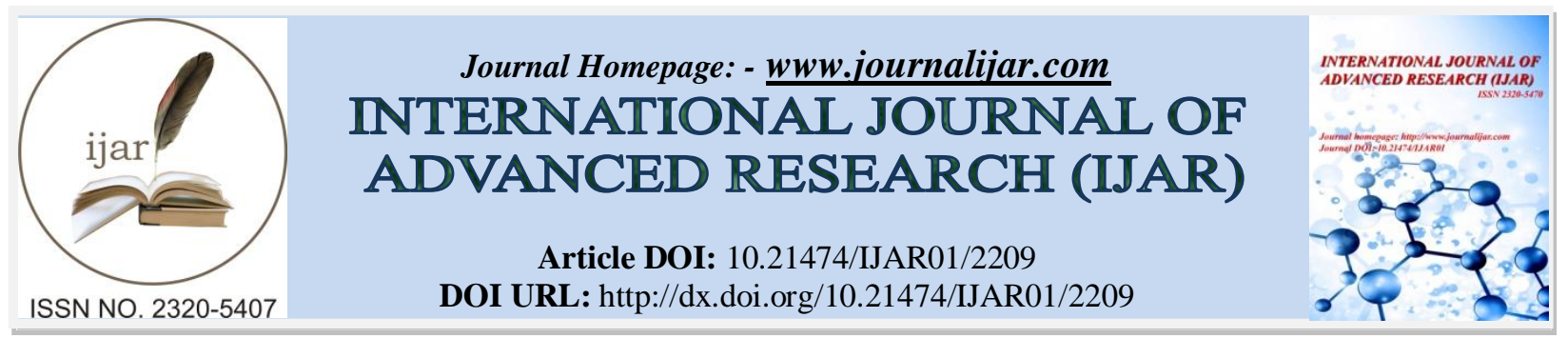

RESEARCH ARTICLE

\title{
HISTOPATHOLOGICAL STUDY OF PERIPHERAL NERVE SHEATH TUMORS.
}

Ghatge R. M, More S. S, Gupta. S, Inamdar A. A, Verma A and Sujata. N.

Post graduate student, Department of Pathology, Dr. D.Y. Patil Medical College, Kolhapur.

\section{Manuscript Info}

Manuscript History

Received: 28 September 2016

Final Accepted: 30 October 2016

Published: November 2016

Key words:-

SCHWANNOMA, NEUROFIBROMA

,MPNST.

\section{Abstract}

Accurate pathological designation of peripheral nerve tumors is important as there is dramatic difference in clinical outcome between benign and malignant tumors.Objective was to classify peripheral nerve sheath tumors as benign and malignant and to study the distribution of peripheral nerve sheath tumors among different age groups, sex and different anatomical locations. The study includes patients clinically diagnosed and treated for peripheral nerve sheath tumours from Dr. D. Y. Patil Hospital and Research center, Kolhapur. Sample size: $\mathbf{5 0}$ cases. Haematoxylin and Eosin stained sections were examined microscopically and histological interpretation were done. IHC was performed as per requirement. This study was conducted between May 2014 to may 2016. 49 out of 50 cases of peripheral nerve sheath tumors were benign, occurring more commonly than MPNST.PNSTs showed almost equal predilection for both the sexes. PNSTs occurred over a wide age range most common between 2nd and 4 th decade of life.

\section{Introduction:-}

Peripheral nervous system - can be defined as nervous system outside the brain and spinal cord. It is an extensive system which includes somatic and autonomic nerves, end-organ receptors and supporting structures. ${ }^{1}$

Schwannoma is a benign, non-recurring tumor arising in cranial nerves, bone, and gastrointestinal tract but mainly in subcutaneous tissue and muscles, with a slight predilection for distal extremities or head and neck region. Histological, is an encapsulated neoplasm having two components, known as Antoni A and B tissue, in variable proportion. $^{2}$

Neurofibroma unlike schwannoma, the neurofibroma is an unencapsulated nerve sheath lesion that may occur in the following forms: (a) a solitary localized nodule;

(b) a diffuse thickening of the skin and subcutaneous tissues; or (c) a "plexiform" tumor, a wormlike, multinodular growth within major or minor nerves. Although only the last form is characteristic of neurofibromatosis, that autosomal-dominant disease may also produce solitary or diffuse lesions. The neurofibroma may be found virtually anywhere in the skin or subcutaneous tissues, and it is usually seen in young adults. ${ }^{3}$

Malignant peripheral nerve sheath tumors (MPNSTs) comprise a group of tumors that arise from peripheral nerves or that display differentiation along the lines of the various elements of the nerve sheath, including Schwann cells, 
perineural fibroblasts, or fibroblasts. Most of these tumors arise on the trunk, extremities, or head and neck regions; they are very rarely located in the abdominal cavity. ${ }^{118 .}$

Malignant peripheral nerve sheath tumors (MPNST'S) of the head and neck comprise $2 \%$ to $6 \%$ of head and neck sarcomas. ${ }^{4}$ Approximately half of these tumors arise de novo, and the other half from nerves involved by neurofibromas as part of type 1 Recklinghausen disease. ${ }^{5}$

Our study focuses on most common primary neoplasms of peripheral nerve and emphasizes the histologic attributes of these benign and malignant nerve sheath tumors, to be familiar with these entities and establish their accurate pathological diagnosis in view of their varying biologic behaviour.

\section{Methodology:-}

The present study was conducted in the Department of Pathology at Dr. D. Y. Patil Medical College, Hospital and Research lnstitute, Kolhapur. This is a prospective study conducted for a period of 2 years from May 2014 to April 2016. The patients were selected at random irrespective of age, sex, socioeconomic status and residence. The eligible patients were briefed about the nature of the study and a written informed consent was obtained from the selected patients. Findings were recorded on predesigned proforma. Biopsy was performed, specimens were processed with routine technique and Haematoxylin \& Eosin staining was performed. Haematoxylin and Eosin stained sections were examined microscopically and histologic interpretation was done.IHC was performed for malignant case.

\section{Results:-}

In present study of the 50 cases, In present study of 50 cases, $49(98 \%)$ cases were benign and $1(2 \%)$ case was malignant.

Of the 50 cases, $25(50 \%)$ cases were Schwannoma,22 (44\%) cases were Neurofibroma,1(2\%) case of Perineurioma, $1(2 \%)$ case of nerve sheath myxoma and $1(2 \%)$ case of MPNST. Of the 50 cases $27(54 \%)$ cases were found in male and $23(46 \%)$ cases were found in females.

PNSTs occurred over a wide age range most common between 2nd and 4th decade of life. Youngest patient being 15 years of age and oldest 70 years of age.

PNSTs showed predilection for extremities especially lower limb followed by head and neck region. Three types of neurofibroma were studied,conventional were $12(55 \%)$ cases, plexiform were $3(13 \%)$ cases and diffuse were $7(32 \%)$ cases.

Three types of schwannoma were studied, conventional were $16(64 \%)$ cases,plexiform were $6(24 \%)$ cases and ancient were $3(12 \%)$ cases.

Table 1:- lesions of peripheral nerve sheath tumors.

\begin{tabular}{|l|l|l|}
\hline LESIONS & NO. OF CASES & PERCENTAGE \\
\hline SCHWANNOMA & $\mathbf{2 5}$ & $\mathbf{5 0 \%}$ \\
\hline NEUROFIBROMA & $\mathbf{2 2}$ & $\mathbf{4 4 \%}$ \\
\hline PERINEURIOMA & $\mathbf{1}$ & $\mathbf{2 \%}$ \\
\hline NERVESHEATH MYXOMA & $\mathbf{1}$ & $\mathbf{2 \%}$ \\
\hline MALIGNANT PERIPHERAL NERVE SHEATH TUMORS & $\mathbf{1}$ & $\mathbf{2 \%}$ \\
\hline TOTAL & $\mathbf{5 0}$ & $\mathbf{1 0 0 \%}$ \\
\hline
\end{tabular}

Table 2:- incidence of benign and malignant peripheral nerve sheath tumors

\begin{tabular}{|l|c|c|}
\hline Type & No of cases & Percentage (\%) \\
\hline Benign PNST & 49 & $98 \%$ \\
\hline Malignant PNST & 1 & $2 \%$ \\
\hline Total & 50 & $100 \%$ \\
\hline
\end{tabular}


Table 3:- sex distribution of peripheral nerve sheath tumors

\begin{tabular}{|c|c|c|}
\hline Sex & No of cases & Percentage (\%) \\
\hline Male & 27 & $54 \%$ \\
\hline Female & 23 & $46 \%$ \\
\hline Total & 50 & $100 \%$ \\
\hline
\end{tabular}

Table 4:- age distribution of peripheral nerve sheath tumors

\begin{tabular}{|c|c|c|}
\hline AGE (years) & NO OF CASES & PERCENTAGE \\
\hline $0-10$ & 0 & 14 \\
\hline $11-20$ & 7 & 10 \\
\hline $21-30$ & 5 & 26 \\
\hline $31-40$ & 13 & 24 \\
\hline $41-50$ & 12 & 16 \\
\hline $51-60$ & 8 & 10 \\
\hline $61-70$ & 5 & 100 \\
\hline Total & 50 & \\
\hline
\end{tabular}

\section{Photographs:-}

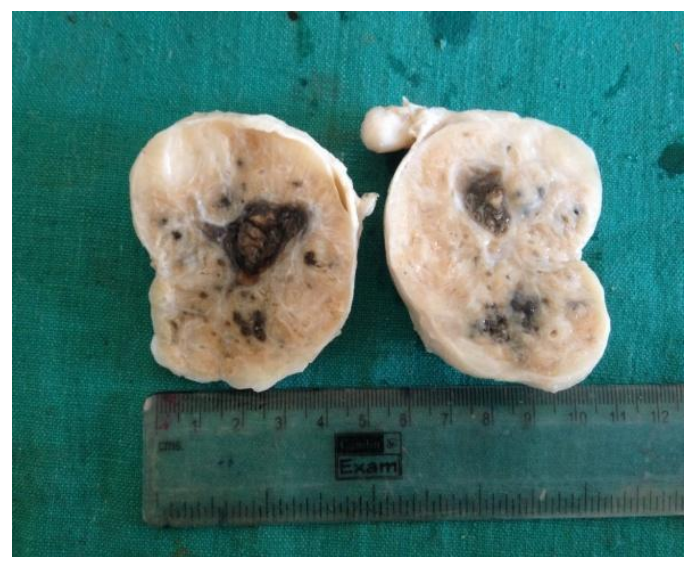

Fig. 1:- Gross specimen of schwannoma

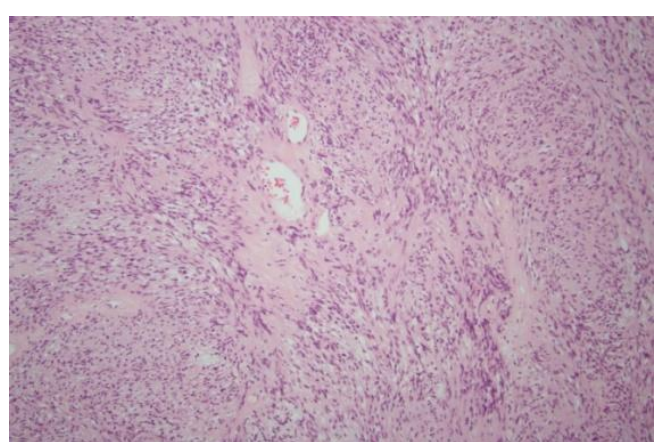

Fig. 2:- Histopathology of schwannoma Photomicrograph showing regimentation of nerve cells along with verocy bodies. (H \& E “10X”). 


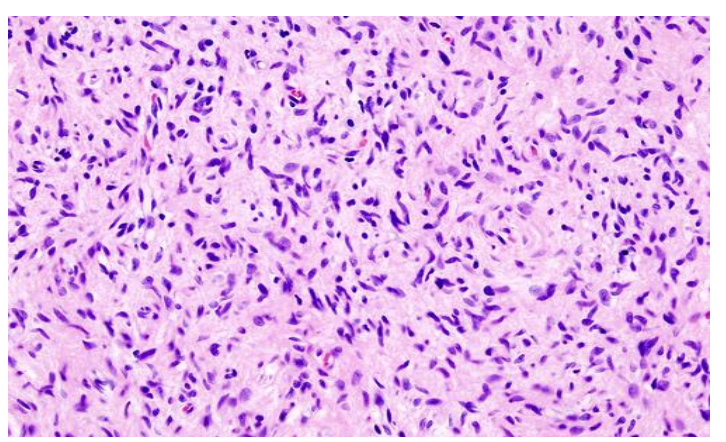

Fig. 3:- Histopathology of Neurofibroma. Photomicrograph showing spindle shaped Schwann cells.(H \& E “40X”).

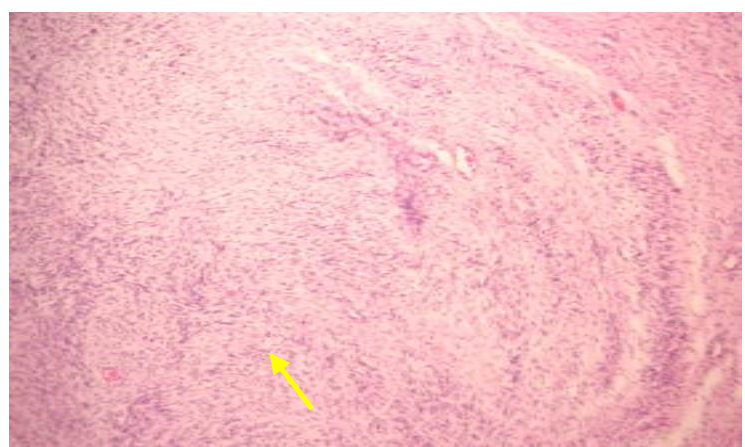

Fig. 4:- MALIGNANT PERIPHERAL NERVE SHEATH TUMOR(MPNST): Photomicrograph showing highly cellular, mitotically active spindle cells, wavy nuclei with diffuse hyperchromasia.

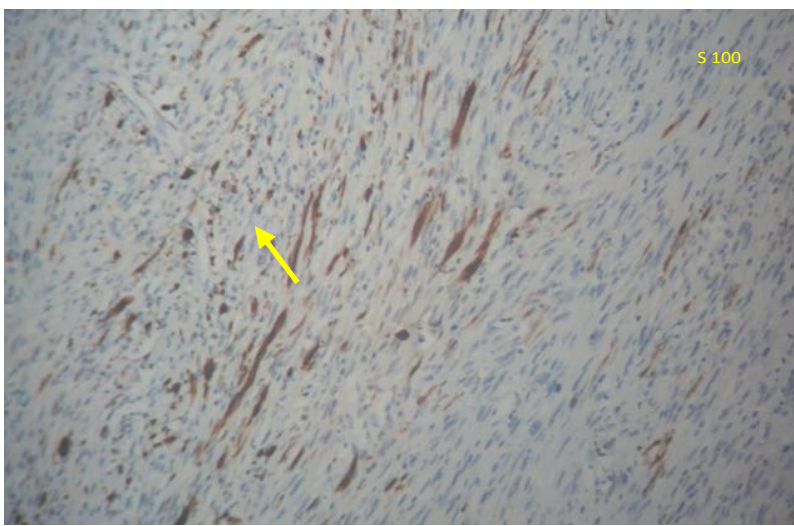

Fig. 5:- MPNST with IHC S100: Photomicrograph showing weak focal S100 staining.

\section{Discussion:-}

In our study, out of 50 cases, 49 were bengin \& 1 was malignant. According to Casadei et al $(1995)^{6}$ and Mohan et al (2003) ${ }^{7}$,no of PNST cases were 1256 and25.In our study total no of PNST were 50,out of which 49 were bengin and 1 was malignant

According to Mohan et al (2003) ${ }^{7}$,no of PNST were 25 with equal frequency in both sexes.In our study,no of cases were 50 with frequency more in males.

According to Johnson et al(1989) $)^{25}$ \& Mohan et al(2003) ${ }^{7}(1997-1998)$,neurofibroma were 32 and 10,schwannoma were 27 and 13,MPNST were 9 and 2 cases.In our study of two years neurofibroma were 22,schwannoma were 25 and MPNST was 1 case.

According to Jordan et al (2003) $)^{8}$ and in our study neurofibroma were 28 and 22 ,schwannoma were 18 and 25 ,ancient schwannoma were 1 and 3,MPNST was 1 in both of them. 
According to Tsutumi et al $(1996)^{9}$, Wei et al $(2005)^{10}$ and Tanna et al $(2007)^{11}$ no of plexiform neurofibroma cases were 1 with location of submandibular gland,uterine cervix and in neck region.In our study 3 were present on chest,thigh and forearm.

According to Varebeke et al $(1996)^{12}$, Beggs et al $(1998)^{13}$ and Zurren et al (2003) ${ }^{14}$ no.of diffuse neurofibroma cases were 1,2 and 1 with locations of neck,ankle and lower back.In our study 7 cases were diffuse with location of extremities,head and neck and trunk.

According to Woodruff et al $(1983)^{17}$, Woodruff et al(2003) ${ }^{18}$,Agaram et al $(2005)^{16}$, Agarwal et al(2007) ${ }^{15}$ and Berg et al (2008) ${ }^{19}$ no of plexiform schwannoma cases were 1,6,24,1 and 22.In our study it was 6 with frequency equal in both sexes and common locations were extremities head and neck regions.

According to Wantanabe et al $(2001)^{20}$, Takeuchi et al (2001) ${ }^{21}$, Mohan et al (2003) ${ }^{7}$,Zhuo et al (2003) ${ }^{23}$, Allison et al $(2005)^{22}$ and Focchi et al $(2007)^{24}$ the no of MPNST cases were 49,23,2,27,5 and 1 respectively.In our case only 1 case was found.

\section{Conclusion:-}

Key issue for the pathologist includes distinguishing schwannomas from neurofibromas, and MPNSTs from cellular schwannoma or neurofibromas. The association of each of these tumors with genetic disorders provides a unique window into discovering basic mechanisms of cell regulation and tumorigenesis that may ultimately shed light on the biology of a much wider array of human disease.

\section{References:-}

1. Jiann-H, Chi-Hsieh Lu, Tong-H, and Hsin-I M:Malignant Peripheral Nerve Sheath Tumor (MPNST) Involving the Sacrum 2007;27(4):179-184

2. Elena Donia M, Luminita Ivan, Maria sultana M: Neurofibroma, Schwannoma or a hybrid tumor of the peripheral nerve sheath 2005, 46(2):113-116

3. Mushtaq Chalkoo, Shahnawaz Ahangar et al. Primary Malignant Peripheral Nerve Sheath Tumor of the Breast-A Case Report: Surgical Science, 2011, 2, 137-139

4. Gupta A, Bansal S, Bhagat S, Bahl A. Malignant peripheral nerve sheath tumor of the cervical vagus nerve in a neurofibromatosis type 1 patient - An unusual presentation.Online J Health Allied Scs. 2010;9(1):10

5. Rosai and Ackerman's volume 2 chap 25soft tissue tumours ): Rosai and Ackerman's Surgical Pathology. $10^{\text {th }}$ edition. Elsevier; 2011: 2128pg

6. Casadei GP, Scheithauer BW, Hirose T, Manfrini M, Houton CV, Wood MB. Cellular Schwannoma : A clinicopathologic, DNA flow cytometric, and proliferation marker study of 70 patients. Cancer 1995;75:110919.

7. Mohan H, Nada R, Tahlan A, Punia RP, Mukherjee KK. Peripheral nerve sheath tumors - a short series with some uncommon variants. Indian J Pathol Microbiol 2003;46(2):204-06

8. Jordan RCK, Regezi JA. Oral spindle cell neoplasms : A review of 307 cases. Oral Surg Oral Med Oral Pathol Oral Radiol Endod 2003;95:717-24.

9. Tsutsumi T, Oku T, Komatsuzaki A. Solitary plexiform neurofibroma of the submandibular salivary gland. J of Laryngol \& Otol 1996;110:1173-75.

10. Wei EX, Saavedra JA, Fowler MR. Plexiform neurofibroma of the uterine cervix :A case report and review of the literature. Arch Pathol Lab Med 2005; 129 : 783-86.

11. Tanna N, Joshi AS, Sidell D, Misra S, Santi M, Collins WO. Plexiform neurofibroma : Pathology Quiz Case1. In : Jezzoni JC, ed. Clinical problem solving : Pathology section. Arch Otolaryngol Head Neck Surg 2007;133:302-05.

12. Varebeke SJDE, Schepper ADE, Hauben E, Declau F, Marck EV, Van De Heyning PH. Subcutaneous diffuse neurofibroma of the neck : a case report. J of Laryngol and Otol 1996;110:182-84.

13. Beggs I, Gilmour HM, Davie RM. Diffuse neurofibroma of the ankle. Clinical Radiology 1998;53:755-59.

14. Van Zuuren EJ, Posma AN. Diffuse neurofibroma on the lower back. J Am Acad Dermatol 2003;48(6):938-40.

15. Agarwal K, Agarwal C, Agarwal M, Harbhajanka A. Plexiform Schwannoma of scalp : a case report with brief review of literature. Indian J Pathol Microbiol 2007;50(4):797-99.

16. Agaram NP, Prakash S, Antonescu CR. Deep-seated plexiform Schwannoma : A pathologic study of 16 cases and comparative analysis with the superficial variety. Am J Surg Pathol 2005;29:1042-48. 
17. Woodruff JM, Funkhouser JW, Marshall ML, Thompson NJ, Godwin TA, Erlandson RA. Plexiform (multinodular) Schwannoma : A tumor simulating the plexiform neurofibroma. Am J Surg Pathol 1983;7(7):691-97.

18. Woodruff JM, Scheithauer BW, Yapicier OK, Raffel C, Amr SS, LaQuaglia MP, et al. Congenital and childhood plexiform (multinodular) cellular Schwannoma : A troublesome mimic of malignant peripheral nerve sheath tumor. Am J Surg Pathol 2003;27(10):1321-29.

19. Berg JC, Scheithauer BW, Spinner RJ, Allen CM, Koutlas IG. Plexiform Schwannoma : A clinicopathologic overview with emphasis on the head and neck region. Hum Pathol 2008;39:633-40.

20. Oda Y, Watanabe T, Tamiya S, Kunukawa N, Masuda K, Tsuneyoshi M. Malignant peripheral nerve sheath tumors : high Ki67 labelling index is the significant prognostic indicator. Histopathology 2001;39:187-97.

21. Takeuchi A, Ushigome S. Diverse differentiation in malignant peripheral nerve sheath tumors associated with neurofibromatosis-1 : An immunohistochemical and ultrastructural study. Histopathology 2001;39:298-309.

22. Allison KH, Patel RM, Goldblum JR. Rubin BP. Superficial malignant peripheral nerve sheath tumor : A rare and challenging diagnosis. Am J Clin Pathol 2005;124:685-92. Zhou H, Coffin CM, Perkins SL, Tripp SR, Liew M, Viskochil DH.

23. Malignant peripheral nerve sheath tumor : A comparison of grade, immunophenotype, and cell cycle / growth activation marker expression in sporadic and neurofibromatosis 1 - related lesions. Am J Surg Pathol 2003;27:1337-45.

24. De Afocchi GR, Cuatrecasas M, Prat J. Malignant peripheral nerve sheath tumor of the uterine corpus : A case report. Int J Gynecol Pathol 2007;26(4):437-40.

25. .Johnson MD, Pratt KJ, Federspiel CF, Whetsell WO. Mast cell and lymphoreticular infiltrates in neurofibromas. Comparison with nerve sheath tumors. Arch Pathol Lab Med 1989;113:1263-70. 